\title{
Financial Development, Trade Openness, and Foreign Direct Investment: A Battle Between the Measures of Environmental Sustainability
}

\author{
Weidong Huo ${ }^{1}$, Muhammad Rizwan Ullah ${ }^{2 *}$, Muhammad Zulfiqar ${ }^{1 *}$, Shahida Parveen ${ }^{3}$ and \\ Umar Kibria ${ }^{2}$ \\ ${ }^{1}$ School of Finance and Trade, Liaoning University, Shenyang, China, ${ }^{2}$ Lyallpur Business School, Government College University, \\ Faisalabad, Pakistan, ${ }^{3}$ Lyallpur Business School, Government College Women University, Faisalabad, Pakistan
}

OPEN ACCESS

Edited by:

Ehsan Elahi,

Shandong University of Technology,

China

Reviewed by: Xinru Han,

Institute of Agricultural Economics and Development (CAAS), China

Tanveer Ahsan,

Rennes School of Business, France

*Correspondence:

Muhammad Rizwan Ullah mrizwanullah77@gmail.com

Muhammad Zulfiqar

muhammadzulfiqar796@yahoo.com

Specialty section:

This article was submitted to

Environmental Economics and

Management,

a section of the journal

Frontiers in Environmental Science

Received: 09 January 2022

Accepted: 24 January 2022

Published: 25 February 2022

Citation:

Huo W, Ullah MR, Zulfigar $M$,

Parveen S and Kibria U (2022)

Financial Development, Trade

Openness, and Foreign Direct

Investment: A Battle Between the

Measures of

Environmental Sustainability.

Front. Environ. Sci. 10:851290.

doi: 10.3389/fenvs.2022.851290
Deterioration in the environmental quality is a major threat to the sustainable development of an economy as it results in serious economic problems and the researchers are conscious about the environment sustainability. They have identified several factors including financial development, inflow of foreign aid, and openness of trade to promote environmental sustainability. Unfortunately, their findings remain inconclusive as they have imperfectly measured environmental sustainability. This study, thus, aims to contribute to the ongoing debate of environmental sustainability by testing the role of financial development, trade openness, and foreign direct investment (FDI) in promoting environmental sustainability by using adjusted net savings as a measure of environmental sustainability. To do this, the study collects data from 1996 to 2019. The study uses financial development, trade openness, and FDI as predictors and environmental sustainability as an outcome variable. The study applies Auto Regressive Distributive Lag (ARDL) methodology to analyze the impact. The findings show positive contributions of financial development, trade openness, and foreign direct investment in promoting environment sustainability. We suggest encouraging trade through lower-taxation programs and increasing competition in the financial markets through privatization and domestic and international liberalization to stimulate environmental sustainability. We also recommend imposing high taxes and penalties on such activities that damage the quality of the environment.

Keywords: financial development, trade openness, foreign direct investment, adjusted net savings, environment sustainability

\section{INTRODUCTION}

Over the past 3 decades, different researchers and policy makers have shown their great interest in promoting economic growth, and the achievement of economic growth remains a prime concern of both developed and developing economies (Ahmed et al., 2020; Ahmed et al., 2021; Meirun et al., 2021; Zhang et al., 2021). Economic growth is usually measured with the traditional GDP which is defined as an increase in per head level of the production of goods and services (Ahmed et al., 2021); 
during this production process, different resources such as mineral, water, and other such resources are extracted from the environment which deteriorate the environmental quality (EQ) (Ncube et al., 2021). Consequently, deterioration in EQ negatively impacts production systems (Elahi et al., 2017; Elahi et al., 2019c; Zhao et al., 2020; Zheng et al., 2020; Peng et al., 2022). This deterioration in EQ is a major warning to an economy's sustainable development (Khan et al., 2021), as it falls out with serious economic consequences like poverty, inequality, food-shortage, etc. (Gwangndi et al., 2016). Henceforth, researchers have become very conscious about environment sustainability (ES), and this issue has gained worldwide attention in recent years (Shen et al., 2019; Sheng et al., 2019; Wang et al., 2019; Huang et al., 2021; Zhong et al., 2021).

Researchers argued that a country does not require advance economic progress, instead, they want a sustainable environment where they can live spontaneously (Tyagi et al., 2014). Consequently, researchers endeavored to identify different factors to promote ES. To some extent they have become successful in exploring the factors having substantial contributions in the reduction of carbon emissions. However, regrettably, their findings remain inconclusive regarding ES. To the best of our knowledge, the major blemish in the prior studies is that they explore the contributions of different factors to the reduction of carbon emissions (Elahi et al., 2022b), instead of testing their contribution to the sustainability of the environment. Researchers assume that the reduction in carbon emissions ultimately improves ES (Ahmed et al., 2021). However, this assumption is not applicable practically, as ES and environmental degradation (ED) are two different dimensions of EQ, a controversial point widely discussed in the literature (Ganda, 2019; Ahmed et al., 2021).

The present study believes that financial development (FD) is among one of the most prominent factors promoting ES. In recent years, numerous studies have been published on financeenvironment nexus. These studies indicate that the availability of finance helps the nations to access advanced machineries having less significant contributions to the level of GHG emissions (Zakaria and Bibi, 2019). In addition to this, the development in a country's financial sector is probable to deliberate the loftier financial services for the environmentally sustainable series at fewer costs and thus reduces the energy impurities which is beneficial for the EQ (Yuxiang and Chen, 2011). Similarly, FD promotes $\mathrm{R}$ and $\mathrm{D}$ activities and investments in cleaner technologies which is again fruitful for the ES (Ahmed et al., 2020; Ahmed et al., 2021). However, adoption of cleaner energy is dependent on the psychological behavior of the population (Elahi et al., 2022a).

Like FD, trade openness (TO) is another key factor that shows substantial contributions to the ES. Due to the openness of trade, a nation can easily get access to the "innovative technologies", which provides a cleaner way of producing goods (Fang et al., 2020). Besides, due to the TO, a nation can get access to economical goods and services which accelerate the shift into a sustainable environment (Ahmed et al., 2020). All at once, the TO accelerates the flow of FDI, which is advantageous for the sustainable environment. It is argued that because of the inflows of FDI, an economy becomes able to invest in several R\&D activities that eventually promote ES. Moreover, FDI has encouraging spillover impacts on innovative machineries and employment growth (Adeel-Farooq et al., 2021). However, summing up the above discussion, the present study expects the significant role of $\mathrm{FD}, \mathrm{TO}$, and FDI in promoting environmental sustainability. Figures 1-3 show the pattern between FD-ES, TO-ES, and FDI-ES, respectively. Figures clearly show that increase in FD, TO, and FDI leads to enhanced ES, hence creating a dire need to empirically estimate this relationship.

We intend to address the following research gaps after reviewing the available literature on the environment. First, we observe that ED and ES are two distinct dimensions of EQ, thus, to the best of our knowledge, the focus of most of the researchers remains on $\mathrm{ED}$, and the area of ES remains less focused on by prior researchers (Ganda, 2019; Ahmed et al., 2020). Second, we figure out that researchers are wrongly interpreting the impact of different factors on ES, as their findings are based on the explicit measures of environment quality, i.e., $\mathrm{CO}_{2}$ or $\mathrm{GHG}$ emissions, which is not an appropriate measure of ES, instead it is an indicator of environmental pollution (Ahmed et al., 2020; Gu et al., 2020a; Gu et al., 2020b; Ali et al., 2021; Zhao et al., 2021; Dornean et al., 2022). Third, though the study believes that some attempts have been made by several researchers to scrutinize the role of FD in ES by using an appropriate proxy of ES (i.e., adjusted net savings), these studies are rare. Fourth, even though the studies on the FDI-ES nexus are very extensive in the available literature that conclude the significant role of FDI in ES, lamentably these conclusions are based on the $\mathrm{CO}_{2}$ emissions (Blanco et al., 2013; Fauzel, 2017; He et al., 2020; Mukhtarov et al., 2021; Usman et al., 2022). To the best of our knowledge the role of FDI in promoting ES (with its appropriate proxy, i.e., adjusted net savings) is a neglected aspect in the ongoing debate of the environment. Last, the collective impact of FDI, FD, and TO is also not investigated on ES particularly for the case of Pakistan using adjusted net savings as an ES measure. Therefore, a more concise understanding on this topic is required. In this regard, the present study constitutes the existing debate of the environment by analyzing the collective impact of FDI, FD, and TO in EQ for the case of Pakistan. Thus, we aim to investigate the impact of FD, TO, and FDI on ES using adjusted net savings as ES measures where the available studies are lacking.

The remaining portion of this research paper is separated as follows: the next section is about the literature review with hypotheses construction, the third section details the data, research, and econometric techniques, while the fourth and fifth sections contain results and conclusion with implications and future avenues, respectively.

\section{LITERATURE REVIEW}

The impact of FD on the environment is well debated in the available literature (Peng et al., 2021a; Peng et al., 2021b; Wang et al., 2021). Most of the researchers have believed that FD 
FDI and ES pattern

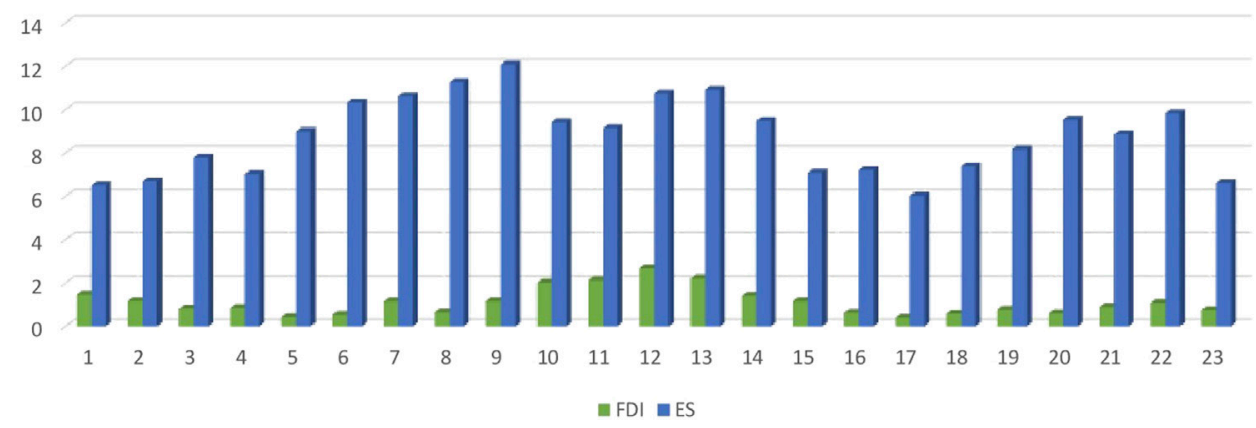

FIGURE 1 | Pattern between FDI and ES

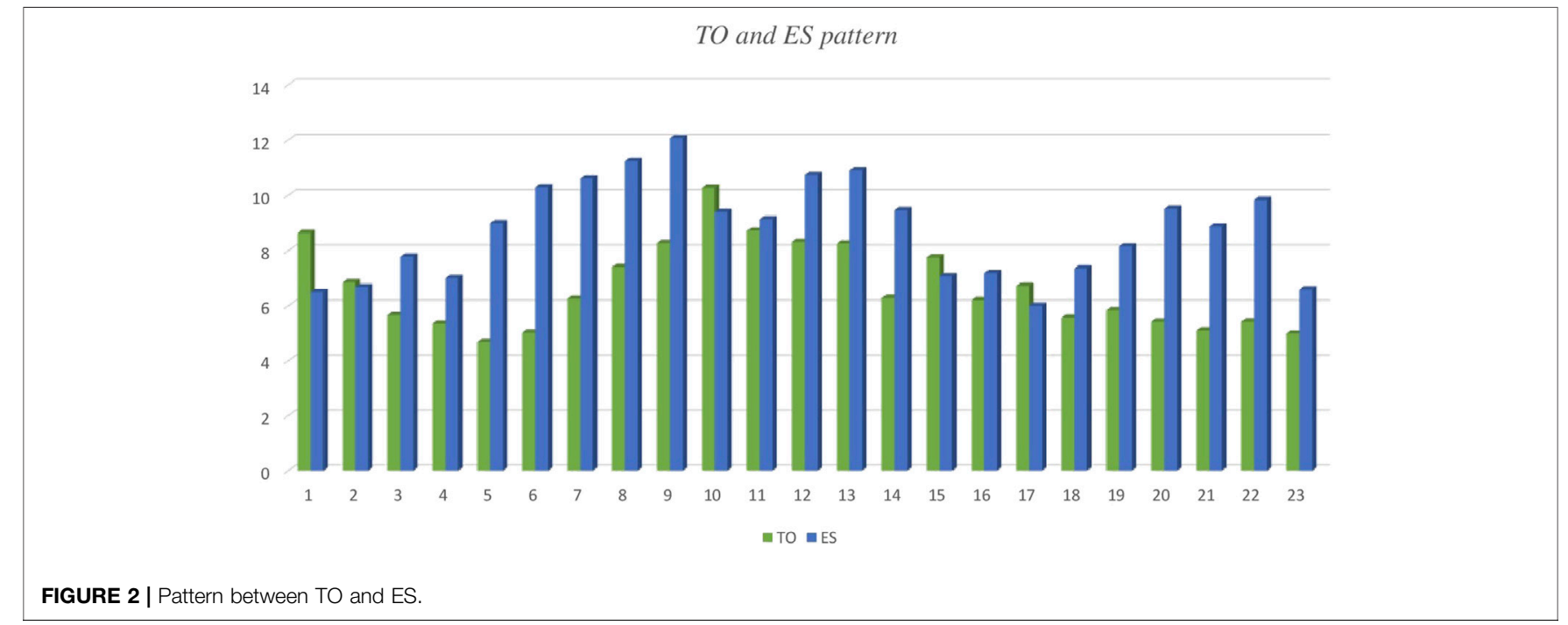

positively contributes to the EQ. For instance, Zakaria and Bibi (2019) conducted research on the panel of South Asian economies over 1984-2015 and found a negative affiliation between FD and the level of $\mathrm{CO}_{2}$ emissions. Similarly, Shahbaz et al. (2016) also found an indirect association between FD and $\mathrm{CO}_{2}$ emissions in the context of Pakistan. The study indicated that FD provides the means to access the environmentally friendly sources of energy, having less significant contributions to the carbon emissions, which in turn promotes ES. Shahbaz et al. (2013) accompanied a study for the case of Malaysia with the aim to identify the contributions of $\mathrm{FD}$ to $\mathrm{CO}_{2}$ reduction. To achieve this purpose, the data for the period of 1971-2008 were utilized. The study applied ARDL to reveal the empirical findings. Results of the study indicated that FD is a significant predictor of ES as it significantly contributes to the reduction of carbon emissions. Yuxiang and Chen (2011) also narrated the significant relationship between FD and ES. The study argued that the progress of a country's financial sector is probable to deliberate the loftier financial services for the environmentally sustainable series at lower costs and thus reduces the energy impurities that lead to ES. Al-Mulali and Sab (2012) also indicated a crucial role of FD in the reduction of GHG emissions to promote ES. However, Ahmed et al. (2020) argued that it is not practically applicable to justify the contributions of FD in ES in the terms of carbon emissions. They claimed that ES and ED are two distinct dimensions of EQ. To justify their claim, the authors analyzed the role of FD and quality of institution on both dimensions of the environment (ES as measured by adjusted net savings and ED as measured by carbon emissions). Findings designated a positive impact of FD and quality institutions on ES, while a negative impact of FD and institutional quality on carbon emissions. Similarly, Usman et al. (2022) conducted a study on FD-ED relation and revealed an indirect link between FD and ED. They claimed that improved EQ is the sign of a financially rich economy. Moreover, Qin et al. (2021) also reported similar findings for the Chinese perspective. Therefore, it is established that: 


\section{FD and ES pattern}

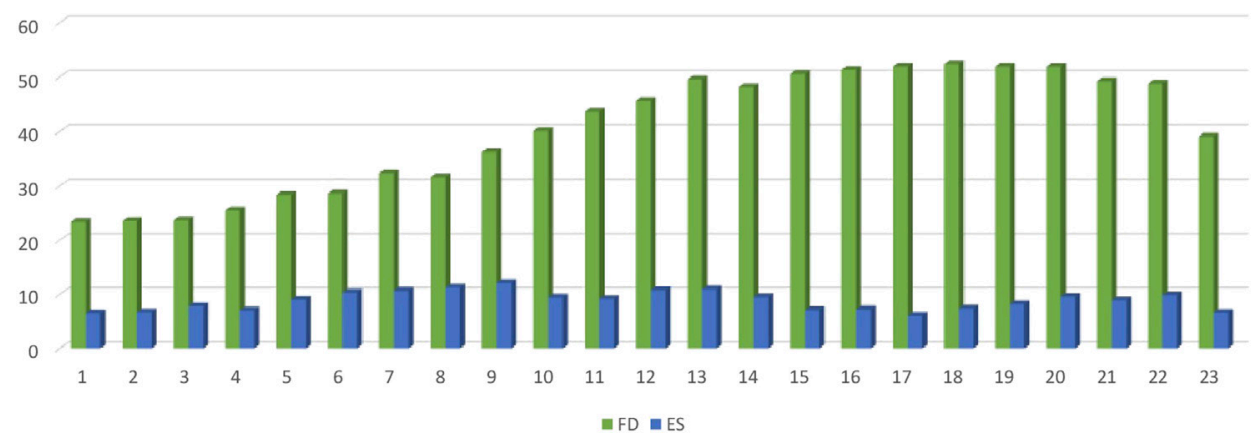

FIGURE 3 | Pattern between FD and ES.

$\mathrm{H}_{1}$ : "There exists a significant relationship between financial development and environmental sustainability."

The debate on the TO-environment nexus is highly crucial for researchers. However, researchers do not come to a definite consensus regarding the influence of TO on ES, as there exists conflicted nature of results in the available literature. Such as, some researchers showed the positive whereas others depicted the negative affiliation between TO and the environment. According to some researchers, TO is a blessing for $\mathrm{EQ}$, while others regard it as a curse. Specifically, Zhao and Yang (2020) indicated that FD significantly contributes to the reduction in GHG emissions which, resultantly, promotes ES. Bayar et al. (2020) utilized the data of the EU for the period of 1995-2017 to examine the relation between TO and GHG emissions. Outcomes of the study revealed the negative connection between TO and GHG emissions. The study argued that the openness of trade provides the means to invest in environmentally friendly projects which is fruitful for a nation's EQ. However, Mahmood et al. (2019) argued that openness of trade deteriorates the EQ in Tunisia. Sebri and Ben-Salha (2014) indicated that openness of trade depreciates the EQ of developing economies. They argued that the trade leads toward the concentration in pollution concentrated activities which in turn increases the level of GHG which is detrimental for the EQ. Jamel and Maktouf (2017) conducted research on 40 European economies and also found that TO significantly contributes to the level of GHG emissions, and hence reduces the ES. Ali et al. (2021) conducted a study on the organization of Islamic cooperation (OIC) economies and confirmed an inverted U-shaped relation between TO and EQ. However, Ahmed et al. (2020) stated ES is a distinct dimension of EQ, and hence argued that researchers are erroneous while measuring the degradation and sustainability with a single proxy (i.e., $\mathrm{CO}_{2}$ or $\mathrm{GHG}$ emissions). The study argued that we cannot conclude the relationship between $\mathrm{TO}$ and ES based on its contributions to $\mathrm{CO}_{2}$ emissions. Hence it is constructed that:

$\mathrm{H}_{2}$ : "There exists a significant relationship between trade openness and environmental sustainability."

Studies on the nexus between FDI and environment are also well documented in the literature. Several researchers have indicated the significant role of FDI in the reduction of carbon emissions that leads toward the ES. For instance, Blanco et al. (2013) collected the data from 13 nations of Latin America for the period of 1980-2007. The prime objective of the study was to identify the contributions of FDI to the $\mathrm{CO}_{2}$ emissions. To achieve this objective, the study applied ARDL. Results of ARDL revealed the negative impact of FDI on $\mathrm{CO}_{2}$ emissions. The study concluded that FDI is advantageous for a nation's ES. He et al. (2020) scrutinized the role of trade and FDI on the emissions of carbon-dioxide for the case of BRICS nations. In this respect, the study collected data for the period of 1996-2017 and applied bootstrap ARDL model to test the hypothesized relationship among the variables. Findings of the study exhibited a direct impact of TO while an indirect impact of FDI on $\mathrm{CO}_{2}$ emissions. Fauzel (2017) also conducted research on FDI- $\mathrm{CO}_{2}$ nexus for the case of the developing state of a small island. The study indicated that the inflows of foreign investments are beneficial for the EQ. They claimed that the inflow of foreign investment provides the means to invest in environmentally friendly sources (i.e., cleaner energy, cleaner technologies, etc.) which less significantly contributes to the GHG emissions and hence promotes ES. Mukhtarov et al. (2021) conducted their research for the case of Azerbaijan for the period 1996-2013 and indicated that FDI has substantial contributions in the reduction of GHG emissions which promotes ES. Jafri et al. (2021) also showed a significant role of FDI in reducing the level of $\mathrm{CO}_{2}$. Dornean et al. (2022) also found a significant relation between FDI and ES. Similarly, Hao and Liu (2015) described that FDI significantly contributes to the reduction of carbon emissions and hence improves the EQ. However, the above studies have used $\mathrm{CO}_{2}$ emission for measuring $\mathrm{ED}$ and $\mathrm{ES}$, which is not good and hence creates a gap. Thus, it is hypothesized that:

$\mathrm{H}_{3}$ : "There exists a significant relationship between foreign direct investment and environmental sustainability."

\section{Theoretical Framework}

The links among the variables of interest is explained using an inverted U-shaped environment Kuznets curve (EKC). The EKC 
TABLE 1 | Measuring the variables.

\begin{tabular}{|c|c|c|}
\hline Variables & Proxy/measurement & References \\
\hline & Explained variable & \\
\hline \multirow[t]{2}{*}{ Environmental sustainability (ES) } & "National adjusted net savings (excluding particular emission damage)" & Ahmed et al. (2020) \\
\hline & Explanatory variables & \\
\hline Financial development (FD) & "Domestic credit to private sector" & Acheampong (2019) \\
\hline Trade openness (TO) & "Imports + Exports (\% of GDP)" & Ahmed et al. (2020) \\
\hline Foreign direct investment (FDI) & "Inflow of foreign investment (\% of GDP)" & Kousar et al. (2020) \\
\hline
\end{tabular}

highlights three important phases, namely the pre-industrial phase, the industrial phase, and the post-industrial phase. The period of pre-industrial stage gives more importance to economic growth rather than EQ. During this phase, a country primarily focuses on promoting the growth of economy at any cost. Thus, during the period of the first phase, inclination in any kind of financial and/or economic activities worsens the EQ of the country. During the industrial period (phase 2), a country reaches the specific threshold level of economic progress, thus they start focusing on those activities and strategies that help them to attain a steady path of economic progress without worsening the EQ. During the third or postindustrial period, the importance is given to the environment sustainability instead of economic growth. Because, at this stage, the country realizes that environment deterioration leads to several economic losses such as inequality, poverty, etc. During the time of this phase, the government of a country starts making strategies (like increasing $\mathrm{R}$ and $\mathrm{D}$ projects and innovations) that aids them to promote environment sustainability. Thus, based on EKC, we expect significant linkages among the study variables.

\section{DATA AND METHODOLOGY}

\section{Data}

The prime objective of this study is to scrutinize the impact that FD, TO, and FDI have on ES in Pakistan. To accomplish this objective, the study acquires data from the World Bank for the period of 1996-2019. The study takes FD, TO, and FDI as explanatory variables while ES is taken as an explained variable. The description of chosen variables is presented in Table 1. The study transforms all the variables into their natural logarithmic form to bring them to a similar unit.

\section{Econometric Techniques}

The following econometric model is used to analyze the hypothesized relationship among the variables of interest (see Equation 1):

$$
\mathrm{ES}=\mathrm{a}_{0}+\mathrm{a}_{1}(\mathrm{FD})_{\mathrm{t}}+\mathrm{a}_{2}(\mathrm{TO})_{\mathrm{t}}+\mathrm{a}_{3}(\mathrm{FDI})_{\mathrm{t}}+\mathrm{u}_{\mathrm{t}}
$$

where "ES is environmental sustainability, FD is financial development, TO is trade openness, FDI is foreign direct investment, $\alpha_{0}$ is intercept, $\alpha_{1}-\alpha_{3}$ are slope coefficients, $u_{t}$ is stochastic error term, and tenotes time period."

The study applies ARDL to analyze the impact. Before this, some cautionary tests (such as test of multicollinearity, heteroscedasticity, and serial correlation) are applied to get error-free results. After this, the study applies augmented dickey fuller (ADF) unit-root test to detect the behavior of series/stationary properties of the data, which is an essential step in time-series methodology. Keeping in mind the nature of the series, bounds co-integration technique, a most appropriate econometric methodology, is applied to test the co-integrating relation among the chosen variables. The functional form of ARDL bounds testing approach is stated in:

$$
\begin{aligned}
(E S)_{t}= & \alpha_{0}+\sum_{i=1}^{q} \lambda_{0}(E S)_{t-i}+\sum_{i=0}^{q} \alpha_{1}(F D)_{t-i}+\sum_{i=0}^{q} \alpha_{2}(T O)_{t-i} \\
& +\sum_{i=0}^{q} \alpha_{3} F D I_{t-i}++u_{t}
\end{aligned}
$$

where ES is environmental sustainability, FD is financial development, TO is trade openness, FDI is foreign direct investment, $\alpha_{0}$ is intercept, $\alpha_{1}-\alpha_{3}$ are the predictors' parameters of independent variables slope coefficients, $u$ is stochastic error or residual term, and $\lambda$ is the parameters of lagged outcome variable as a predictor in the model, whereas $t$ denotes time.

Bounds test estimates the co-integrating affiliation among the chosen variables by assuming "no-co-integration" under its null hypothesis $\left(\mathrm{H}_{0}\right)$, against alternative $\left(\mathrm{H}_{1}\right)$ of "co-integrated series", and uses F-statistics to conclude the results. For example, the study rejects $\mathrm{H}_{0}$ as "no co-integration" if the F-score is higher than the upper bound, which confirms the existence of co-integration among modeled variables. Contrarily, co-integration will not exist if the vice versa situation occurs.

Though, after affirming a long-run association among the selected variables, we acquire short-run dynamic coefficients by assessing ECM (error correction model) in:

$$
\begin{aligned}
(\Delta E S)_{t}= & \alpha_{0}+\sum_{i=1}^{q} \lambda_{0}(\Delta E S)_{t-i}+\sum_{i=0}^{q} \alpha_{1}(\Delta F D)_{t-i} \\
& +\sum_{i=0}^{q} \alpha_{2}(\Delta T O)_{t-i}+\sum_{i=0}^{q} \alpha_{3}(\Delta F D I)_{t-i} \\
& +\sum_{i=0}^{q} \psi(E C M)_{t-1}+e_{t}
\end{aligned}
$$


TABLE 2 | Descriptive statistics.

\begin{tabular}{lcccc}
\hline Particulars & LnES & InFD & InFDI & InTO \\
\hline Mean & 2.150820 & 3.656798 & -0.043524 & 1.871983 \\
Median & 2.196881 & 3.775693 & -0.113324 & 1.833427 \\
Maximum & 2.490867 & 3.958634 & 0.981450 & 2.330128 \\
Minimum & 1.793235 & 3.152840 & -0.960173 & 1.545903 \\
Std. Dev & 0.203303 & 0.297422 & 0.533061 & 0.220531 \\
Skewness & -0.126259 & -0.560889 & 0.221758 & 0.364333 \\
Kurtosis & 1.776699 & 1.766818 & 2.255564 & 1.980859 \\
Jarque-Bera & 1.495221 & 2.663326 & 0.719604 & 1.504204 \\
Probability & 0.473497 & 0.264038 & 0.697815 & 0.471375
\end{tabular}

where $\Delta$ is the operator difference, $\psi$ represents the speed of adjustment, $\mathrm{ECM}_{\mathrm{t}-1}$ is error correction model, as are all shortrun dynamic coefficients of the convergence of model to stability, and $e_{t}$ is the residual term supposed to be normally distributed (Elahi et al., 2019a; Elahi et al., 2019b; Elahi et al., 2020; Elahi et al., 2021a; Elahi et al., 2021b; Gu et al., 2021).

\section{RESULTS}

\section{Descriptive Statistics}

The outputs of descriptive statistics are reported in Table 2, which shows the largest, smallest, averages (mean and median), and standard deviation values. Moreover, the scores of skewness, kurtosis, and Jarque-Bera (along with probability values) are also reported in this table. The test of Jarque-Bera is used to detect the residuals' normality with having $\mathrm{H} 0$ of "normal distribution of residuals". The insignificant test statistic of Jarque-Bera acknowledges the acceptance of the null hypothesis, which states the normal distribution of data.

\section{Diagnostic Tests}

As it is already discussed that the detection of econometric errors is crucial to obtain the desired results, therefore, prior to analysis, we employ some diagnostic tests, reported in Table 3. Results of panel A show that the "problem of multicollinearity" does not exist in the data as the coefficient of correlation among predictors is less than 0.5. Results of panel B stated that the problems of heteroscedasticity and serial correlation do not exist in the data as the probability values of heteroscedasticity and serial correlation are insignificant.

\section{Test of Stationarity}

Test of stationarity is another crucial step before the empirical estimations. We use ADF, an extensively used unit root test to observe the stationary properties of the data. The ADF test examines the problem of unit root under $\mathrm{H}_{0}$ of "non-stationary series", against the $\mathrm{H}_{1}$ of "stationary series". Results of ADF are exhibited in Table 4. We employ the test on level and by taking the first difference of data in two cases, with intercept and with intercept and trend. Results of $\mathrm{ADF}$ indicate that $\operatorname{lnFD}$ and $\operatorname{lnES}$ suffer from the problem of unit-root at level under two conditions of with intercept and with intercept and trend (as depicted by insignificant $p$-values). While $\ln$ TO and $\operatorname{lnFDI}$ are free from this problem. Nonetheless, when we apply this test by taking the first difference of the data, $\operatorname{lnFD}$ and $\operatorname{lnES}$ become stationary at the level of $1 \%$. $\ln$ TO and $\operatorname{lnFDI}$ are also stationary at the first difference. This indicates that $\operatorname{lnFD}$ and $\operatorname{lnES}$ are integrated of order 1, i.e., I (1), while $\operatorname{lnTO}$ and $\operatorname{lnFDI}$ are integrated of order 0 , and order 1, i.e., I (0) and I (1). Thus, we conclude that the data for the present study are stationary at mix order.

\section{Test of Co-Integration}

To test the long run association, we apply bounds co-integration test whose outputs are presented in Table 5. This test has the $\mathrm{H}_{0}$ of "no co-integration among variables", whereas rejecting $\mathrm{H}_{0}$ means confirming the long-term affiliation between variables. Outputs in Table $\mathbf{5}$ demonstrate that F-scores are higher than the scores of critical upper-bounds, rejecting $\mathrm{H}_{0}$, which confirms the long-term affiliation among the modeled variables.

\begin{tabular}{|c|c|c|c|c|}
\hline \multicolumn{5}{|c|}{ Panel A: Multicollinearity } \\
\hline Variables & InES & InFD & InFDI & $\operatorname{lnTO}$ \\
\hline $\operatorname{lnFD}$ & 0.105170 & 1 & - & - \\
\hline InFDI & 0.331559 & 0.054872 & 1 & - \\
\hline InTO & 0.189357 & 0.254548 & 0.1122391 & 1 \\
\hline \multicolumn{2}{|c|}{ Breusch-Godfrey Serial Correlation } & $\begin{array}{c}\text { Test statistic } \\
0.5456\end{array}$ & $\begin{array}{c}\text { Prob. Value } \\
0.2684\end{array}$ & $\begin{array}{l}\text { Decision } \\
\text { "No serial correlation" }\end{array}$ \\
\hline \multicolumn{5}{|c|}{ Panel C: Heteroscedasticity } \\
\hline \multicolumn{2}{|c|}{ Breusch-Pagan-Godfry HSK } & $\begin{array}{c}\text { Test statistic } \\
1.9465\end{array}$ & $\begin{array}{c}\text { Prob. Value } \\
0.1142\end{array}$ & $\begin{array}{l}\text { Decision } \\
\text { "No HSK" }\end{array}$ \\
\hline
\end{tabular}


TABLE 4 | Augmented Dickey Fuller test.

\begin{tabular}{|c|c|c|c|c|c|}
\hline \multirow[t]{2}{*}{ Variables } & \multicolumn{2}{|c|}{ Level } & \multicolumn{2}{|c|}{ First difference } & \multirow[t]{2}{*}{ Decisior } \\
\hline & Intercept & Intercept and trend & Intercept & Intercept and trend & \\
\hline $\operatorname{lnFD}$ & 2.1322 & 2.4121 & $-3.9845^{\star \star \star}$ & $-3.8744^{\star \star \star}$ & I (1) \\
\hline InTO & $-3.0940^{\star \star}$ & $-3.6600^{\star \star}$ & $-3.2469^{\star \star \star}$ & $-4.5528^{\star \star \star}$ & I (0), I (1) \\
\hline InFDI & $-3.7567^{\star \star}$ & $-3.7284^{\star \star}$ & $-3.8849^{\star \star \star}$ & $-3.9495^{\star \star \star}$ & I (0), I (1) \\
\hline InES & -2.1271 & -2.0598 & $-4.0036^{\star \star \star}$ & $-4.1714^{\star \star \star}$ & I (1) \\
\hline
\end{tabular}

Note: "**, **, and ${ }^{* *}$ are the levels of significance at 10, 5, and 1\%, respectively."

TABLE 5 | Bounds co-integration test.

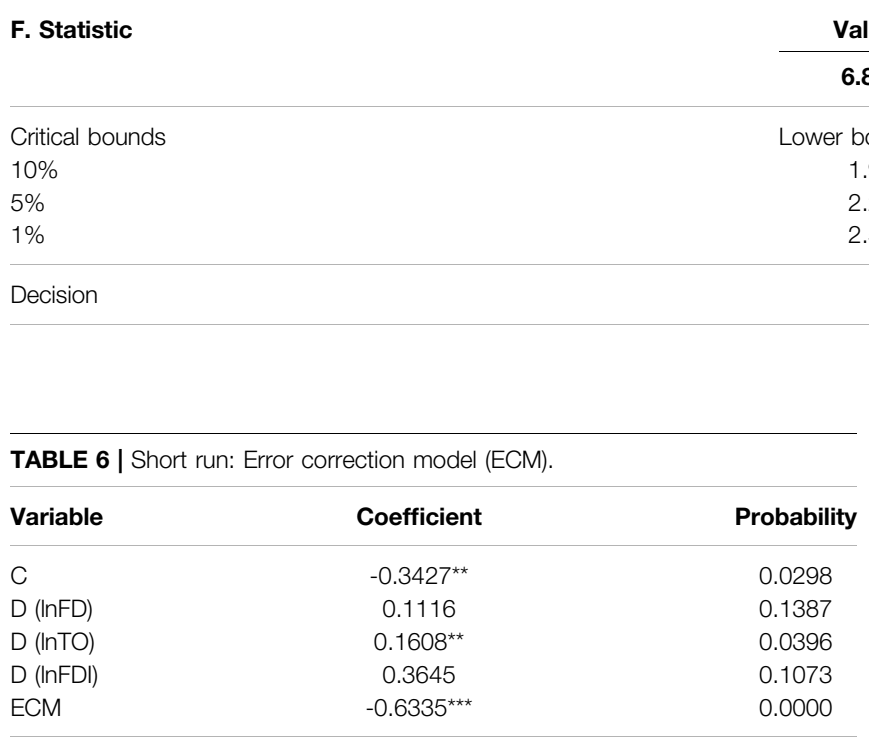

Note: ${ }^{* *},{ }^{* *}$, and ${ }^{* * *}$ are the levels of significance at 10,5 , and 1\%, respectively."

\section{Short-Run Results: Error Correction Model} After the confirmation of co-integration relation among variables, we move toward the short-run estimations reported in Table 6. In the short run, we are only interested to know about the speed of adjustment, shown by the value of ECM. ECM shows how much disequilibrium between short-term and long-term ES can be corrected within a year. The value of ECM $(-0.6335$, significant at the level of $1 \%$ ) reveals that $63.35 \%$ inconsistency or the dis-equilibrium between short-term and long-term ES could be corrected within a year.

\section{Long-Run Results: Hypotheses Testing}

Table 7 presents the outputs of long-run results. The coefficient of $\ln F D\left(\alpha_{1}=0.9700\right)$ is significantly positive at the $5 \%$ level. This indicates the positive relationship between $\operatorname{lnFD}$ and $\ln E S$ in the long run. Results state that $1 \%$ rise in $\operatorname{lnFD}$ leads to a $0.97 \%$ increase in ES. Thus, $\mathrm{H}_{1}$ is acknowledged. Similarly, the coefficient of $\operatorname{lnTO}\left(\alpha_{2}=\right.$ 1.0348) is also positive, which indicates the positive connection between $\operatorname{lnTO}$ and $\operatorname{lnES}$. Results exhibit that $1 \%$ inclination in $\operatorname{lnTO}$ brings $1.03 \%$ increment in ES, hence supporting $\mathrm{H}_{2}$. Finally, the coefficient of $\ln$ FDI $\left(\alpha_{3}=\right.$ 1.5071 ) revels that increase in lnFDI positively contributes to

\begin{tabular}{|c|c|c|c|}
\hline Variable & Coefficient & Prob & Decision \\
\hline $\operatorname{lnFD}$ & $0.9700^{\star \star}$ & 0.0201 & $\mathrm{H}_{1}$ : Supported \\
\hline InTO & $1.0348^{\star \star \star}$ & 0.0029 & $\mathrm{H}_{2}$ : Supported \\
\hline InFDI & $1.5071^{\star}$ & 0.0894 & $\mathrm{H}_{3}$ : Supported \\
\hline \multicolumn{2}{|c|}{$R^{2}$} & 0.7643 & \\
\hline \multicolumn{2}{|c|}{ Adj. $R^{2}$} & 0.7584 & \\
\hline
\end{tabular}

Note: "** **, and ${ }^{* *}$ are the levels of significance at 10,5 , and $1 \%$, respectively."

the $\operatorname{lnES}$. This exhibits that $1 \%$ growth in $\operatorname{lnFDI}$ tends to improve $\operatorname{lnES}$ by $1.51 \%$. Thus, confirming $\mathrm{H}_{3}$. Besides, the score of adjusted R2 reveals that $75.84 \%$ deviation in $\operatorname{lnES}$ is mutually explained by $\ln F D$, $\ln \mathrm{TO}$, and $\ln \mathrm{FDI}$.

\section{Models' Stability}

After completing the estimations, the test of a model's stability is of utmost important. CUSUM and CUSUM-SQUARE test are used to test the model's stability. Figure 4 shows that the plots of CUSUM and CUSUM-SQUARE lie within the band of critical lines (within red lines). Hence, the model of the present study is stable to recommend significant policy implications.

\section{DISCUSSION AND CONCLUSION}

Deterioration in EQ is a significant challenge to an economy's sustainable growth as it results in substantial economic difficulties such as poverty, inequality, and food scarcity. As a result, researchers are concerned about ES. The researchers discovered a variety of characteristics that contribute to ES, including financial development, foreign assistance inflow, and 


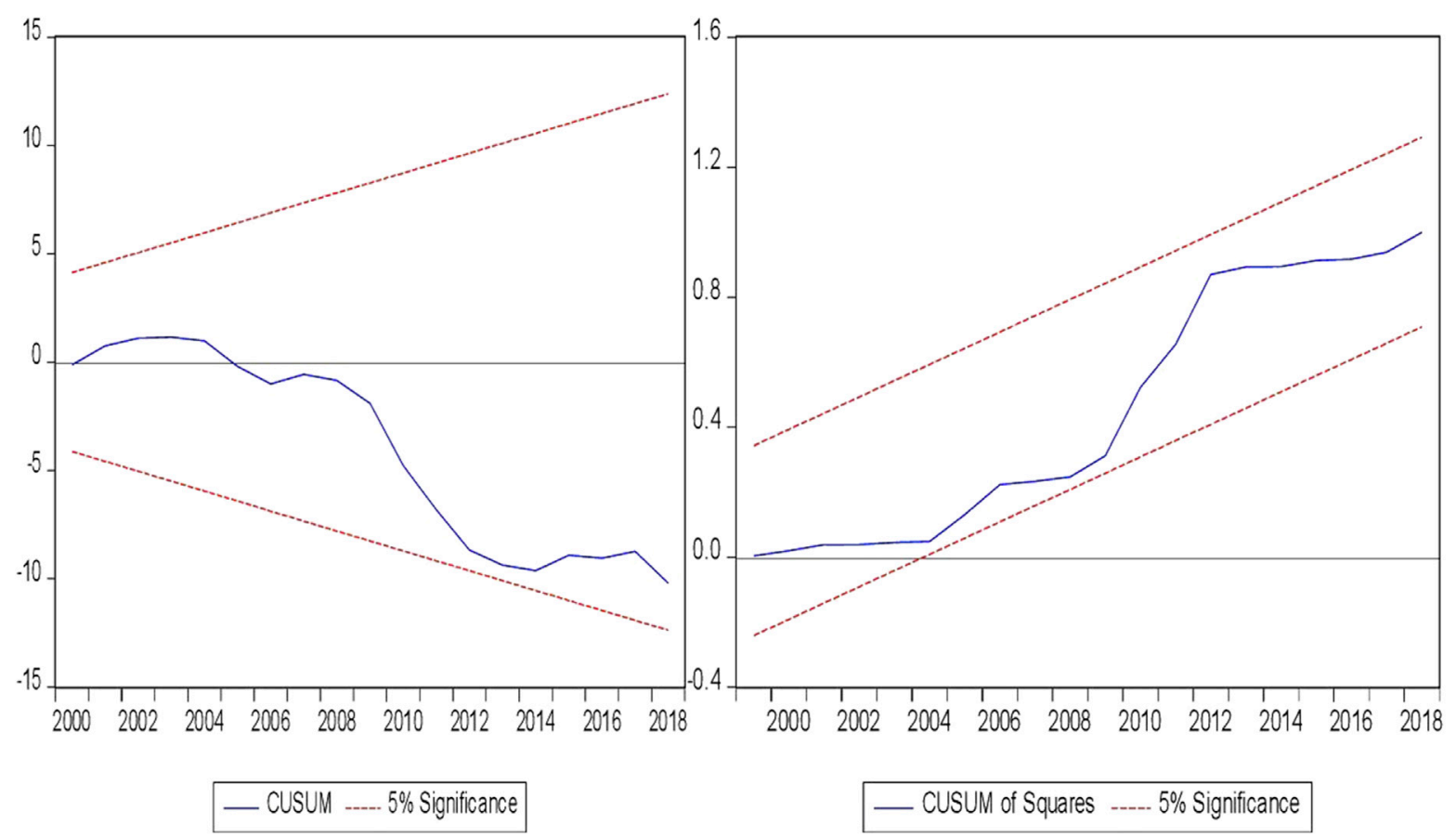

FIGURE 4 | CUSUM and SCUSUM-SQUARE-Model's stability test.

trade openness. Unfortunately, their conclusions remain ambiguous due to their incorrect interpretation of the function of many components in ES. To our knowledge, the significant gap in earlier research is that they examined the contributions of various aspects to carbon emission reduction rather than their contribution to ES. Thus, this study aims to add to the ongoing discussion over EQ by examining the impact of FD, TO, and FDI on ES using adjusted net savings as the ES measure. The study does this by obtaining data from WDI over the period 1996-2019. FD, TO, and FDI were employed as explanatory factors, whereas ES was used as an outcome variable. The study analyzes the impact by using ARDL.

The findings of the study are imperative. First, results show positive impact of FD on ES. The justification behind this relationship is that the development in a country's financial sector is probably to deliberate the loftier financial services for the environmentally sustainable series at low cost and thus reduces the energy impurities which is beneficial for the EQ. Moreover, financial development promotes $\mathrm{R}$ and $\mathrm{D}$ activities and investments in cleaner technologies which is fruitful for the environmental sustainability. Results of the study are aligned with prior researchers (Yuxiang and Chen, 2011; AlMulali and Sab, 2012; Ganda, 2019; Ahmed et al., 2020; Ahmed et al., 2021; Qin et al., 2021; Usman et al., 2022). Second, results of the study showed that TO also has positive contributions to the ES. This is because the openness of trade provides the means to invest in environmentally friendly projects which is advantageous for a nation's EQ. Additionally, due to the trade openness nations can access the economical goods and services which accelerates the shift into a sustainable environment.
Results are similar to past findings (Mahmood et al., 2019; Ahmed et al., 2020; Zhao and Yang, 2020; Ali et al., 2021). Finally, findings also reveal the positive connection between FDI and ES. The underpinning reason behind this is that FDI has encouraging spillover effects on advanced machineries and employment growth. Moreover, it allows the transfer of technologies, predominantly in the form of new capital diversities, which resultantly permits a country to invest in different R\&D activities which ultimately promotes environmental sustainability. Findings are supported with past studies (Blanco et al., 2013; Fauzel, 2017; Jafri et al., 2021; Mukhtarov et al., 2021; Dornean et al., 2022).

Based on the results, we offer the following policy suggestions. First, we suggest that the government should promote the trade through lower taxation programs to promote the ES. Second, the study suggests that the government should expand the competition in financial markets through privatization and domestic and international liberalization. This leads to the development in the financial sector of a country, which in turn promotes the ES. Third the study suggests that government authorities should impose high excises and penalties on such activities that damage the quality of the environment. Similarly, the government should also fund environmentally friendly campaigns to promote ES. This will ultimately improve the EQ. Fourth, the study suggests that the government should start renewable projects to attract the foreign investor which helps increase the flow of foreign money in the home nation which will be gainful for the EQ. Finally, the study suggests imposing a carbon excise on the production and consumption of carbon-emitting technologies to promote investments in low carbon technologies production. 
We offer profound insights into the role of FD, TO, and FDI in promoting ES by using its appropriate measure. However, we faced some limitations which impending scholars can address. This study is conducted in a Pakistani context. Nonetheless, the effect of these factors varies from nation to nation. Thus, the study suggests to future researchers to conduct replicas of this study for other developing nations as well. The study further suggests that upcoming researchers can conduct cross-country analysis by utilizing the data of different developed and developing economies. Finally, the study offers future researchers to compare the effects of FD, FDI, and TO on environment sustainability (measured by adjusted net savings) as well as environment degradation (measured by $\mathrm{CO}_{2}$ ) to provide more projecting insights.

\section{DATA AVAILABILITY STATEMENT}

The raw data supporting the conclusions of this article will be made available by the authors, without undue reservation.

\section{REFERENCES}

Acheampong, A. O. (2019). Modelling for Insight: Does Financial Development Improve Environmental Quality? Energ. Econ. 83, 156-179. doi:10.1016/j. eneco.2019.06.025

Adeel-Farooq, R. M., Riaz, M. F., and Ali, T. (2021). Improving the Environment Begins at Home: Revisiting the Links between FDI and Environment. Energy 215, 119150. doi:10.1016/j.energy.2020.119150

Ahmed, F., Kousar, S., Pervaiz, A., and Ramos-Requena, J. P. (2020). Financial Development, Institutional Quality, and Environmental Degradation Nexus: New Evidence from Asymmetric ARDL Co-Integration Approach. Sustainability 12 (18), 7812. doi:10.3390/su12187812

Ahmed, F., Kousar, S., Pervaiz, A., and Shabbir, A. (2021). Do institutional Quality and Financial Development Affect Sustainable Economic Growth? Evidence from South Asian Countries. Borsa Istanbul Rev. 22, 189-196. doi:10.1016/j.bir.2021.03.005

Ali, S., Yusop, Z., Kaliappan, S. R., and Chin, L. (2021). Trade-Environment Nexus in OIC Countries: Fresh Insights from Environmental Kuznets Curve Using GHG Emissions and Ecological Footprint. Environ. Sci. Pollut. Res. 28 (4), 4531-4548. doi:10.1007/s11356-020-10845-6

Al-Mulali, U., and Sab, C. N. B. C. (2012). The Impact of Energy Consumption and CO2 Emission on the Economic and Financial Development in 19 Selected Countries. Renew. Sustain. Energ. Rev. 16 (7), 4365-4369. doi:10.1016/j.rser.2012.05.017

Bayar, Y., Maxim, L., and Maxim, A. (2020). Financial Development and $\mathrm{CO}_{2}$ Emissions in post-transition European Union Countries. Sustainability 12 (7), 2640. doi:10.3390/su12072640

Blanco, L., Gonzalez, F., and Ruiz, I. (2013). The Impact of FDI on $\mathrm{CO}_{2}$ Emissions in Latin America. Oxford Develop. Stud. 41 (1), 104-121. doi:10.1080/13600818. 2012.732055

Dornean, A., Chiriac, I., and Rusu, V. D. (2022). Linking FDI and Sustainable Environment in EU Countries. Sustainability 14 (1), 196. doi:10.3390/su14010196

Elahi, E., Zhang, L., Abid, M., Javed, M. T., and Xinru, H. (2017). Direct and Indirect Effects of Wastewater Use and Herd Environment on the Occurrence of Animal Diseases and Animal Health in Pakistan. Environ. Sci. Pollut. Res. 24 (7), 6819-6832. doi:10.1007/s11356-017-8423-9

Elahi, E., Weijun, C., Jha, S. K., and Zhang, H. (2019a). Estimation of Realistic Renewable and Non-renewable Energy Use Targets for Livestock Production Systems Utilising an Artificial Neural Network Method: A Step towards Livestock Sustainability. Energy 183, 191-204. doi:10.1016/j.energy.2019.06.084

Elahi, E., Weijun, C., Zhang, H., and Abid, M. (2019b). Use of Artificial Neural Networks to rescue Agrochemical-Based Health Hazards: a Resource

\section{AUTHOR CONTRIBUTIONS}

Conceptualization, done by MRU and WH; methodology, formed by MRU; software and validation, performed by $\mathrm{WH}$; formal analysis done by MRU; investigation, resources, and data curation, performed by MZ; writing-original draft preparation done by United Kingdom and SP; writing-review and editing by SP and United Kingdom; visualization and supervision by MRU and MZ.

\section{FUNDING}

Supported by Liaoning Revitalization Talents Program (XLYC2002116).

\section{ACKNOWLEDGMENTS}

We gratefully thank our universities and colleagues who helped us to complete this manuscript.

Optimisation Method for Cleaner Crop Production. J. Clean. Prod. 238, 117900. doi:10.1016/j.jclepro.2019.117900

Elahi, E., Weijun, C., Zhang, H., and Nazeer, M. (2019c). Agricultural Intensification and Damages to Human Health in Relation to Agrochemicals: Application of Artificial Intelligence. Land Use Policy 83, 461-474. doi:10.1016/j.landusepol.2019.02.023

Elahi, E., Khalid, Z., Weijun, C., and Zhang, H. (2020). The Public Policy of Agricultural Land Allotment to Agrarians and its Impact on Crop Productivity in Punjab Province of Pakistan. Land Use Policy 90, 104324. doi:10.1016/j. landusepol.2019.104324

Elahi, E., Khalid, Z., Tauni, M. Z., Zhang, H., and Lirong, X. (2021a). Extreme Weather Events Risk to Crop-Production and the Adaptation of Innovative Management Strategies to Mitigate the Risk: A Retrospective Survey of Rural Punjab, Pakistan. Technovation, 102255. doi:10.1016/j.technovation.2021.102255

Elahi, E., Zhang, H., Lirong, X., Khalid, Z., and Xu, H. (2021b). Understanding Cognitive and Socio-Psychological Factors Determining Farmers' Intentions to Use Improved Grassland: Implications of Land Use Policy for Sustainable Pasture Production. Land Use Policy 102, 105250. doi:10.1016/j.landusepol.2020.105250

Elahi, E., Khalid, Z., and Zhang, Z. (2022a). Understanding Farmers' Intention and Willingness to Install Renewable Energy Technology: A Solution to Reduce the Environmental Emissions of Agriculture. Appl. Energ. 309, 118459. doi:10. 1016/j.apenergy.2021.118459

Elahi, E., Zhang, Z., Khalid, Z., and Xu, H. (2022b). Application of an Artificial Neural Network to Optimise Energy Inputs: An Energy- and Cost-Saving Strategy for Commercial Poultry Farms. Energy 244, 123169. doi:10.1016/j.energy.2022.123169

Fang, Z., Huang, B., and Yang, Z. (2020). Trade Openness and the Environmental Kuznets Curve: Evidence from Chinese Cities. World Econ. 43 (10), 2622-2649. doi:10.1111/twec. 12717

Fauzel, S. (2017). The Impact of FDI on $\mathrm{CO}_{2}$ Emission in a Small Island Developing State: A Cointegration Approach. Econ. Busin. Lett. 6 (1), 6-13.

Ganda, F. (2019). The Environmental Impacts of Financial Development in OECD Countries: A Panel GMM Approach. Environ. Sci. Pollut. Res. 26 (7), 6758-6772. doi:10.1007/s11356-019-04143-z

Gu, H., Bian, F., and Elahi, E. (2020a). Effect of Air Pollution on Female Labor Supply: An Empirical Analysis Based on Data of Labor Force Dynamic Survey of China. Soc. Work Public Health 35, 187-196. doi:10.1080/19371918.2020.1764433

Gu, H., Yan, W., Elahi, E., and Cao, Y. (2020b). Air Pollution Risks Human Mental Health: an Implication of Two-Stages Least Squares Estimation of Interaction Effects. Environ. Sci. Pollut. Res. 27 (2), 2036-2043. doi:10.1007/s11356-019-06612-x

Gu, H., Bian, F., and Elahi, E. (2021). Impact of Availability of Grandparents' Care on Birth in Working Women: An Empirical Analysis Based on Data of Chinese 
Dynamic Labour Force. Child. Youth Serv. Rev. 121, 105859. doi:10.1016/j. childyouth.2020.105859

Gwangndi, M. I., Muhammad, Y. A., and Tagi, S. M. (2016). The Impact of Environmental Degradation on Human Health and its Relevance to the Right to Health under International Law. Eur. Sci. J. 12 (10), 485-503. doi:10.19044/esj.2016.v12n10p485

Hao, Y., and Liu, Y.-M. (2015). Has the Development of FDI and Foreign Trade Contributed to China's $\mathrm{CO}_{2}$ Emissions? an Empirical Study with Provincial Panel Data. Nat. Hazards 76 (2), 1079-1091. doi:10.1007/s11069-014-1534-4

He, F., Chang, K.-C., Li, M., Li, X., and Li, F. (2020). Bootstrap ARDL Test on the Relationship Among Trade, FDI, and $\mathrm{CO}_{2}$ Emissions: Based on the Experience of BRICS Countries. Sustainability 12 (3), 1060. doi:10.3390/su12031060

Huang, Q., Peng, B., Elahi, E., and Wan, A. (2021). Evolution and Driving Mechanism of Ecological Security Pattern: A Case Study of Yangtze River Urban Agglomeration. Integr. Environ. Assess. Manag. 17, 573-583. doi:10.1002/ieam.4358

Jafri, M. A. H., Abbas, S., Abbas, S. M. Y., and Ullah, S. (2021). Caring for the Environment: Measuring the Dynamic Impact of Remittances and FDI on $\mathrm{CO}_{2}$ Emissions in China. Environ. Sci. Pollut. Res. 29, 9164-9172. doi:10.1007/s11356-021-16180-8

Jamel, L., and Maktouf, S. (2017). The Nexus between Economic Growth, Financial Development, Trade Openness, and $\mathrm{CO}_{2}$ Emissions in European Countries. Cogent Econ. Finance 5 (1), 1341456. doi:10.1080/23322039.2017.1341456

Khan, I., Hou, F., and Le, H. P. (2021). The Impact of Natural Resources, Energy Consumption, and Population Growth on Environmental Quality: Fresh Evidence from the United States of America. Sci. Total Environ. 754, 142222. doi:10.1016/j.scitotenv.2020.142222

Kousar, S., Ahmed, F., López García, M. D. L. N., and Ashraf, N. (2020). Renewable Energy Consumption, Water Crises, and Environmental Degradation with Moderating Role of Governance: Dynamic Panel Analysis under CrossSectional Dependence. Sustainability 12 (24), 10308. doi:10.3390/su122410308

Mahmood, H., Maalel, N., and Zarrad, O. (2019). Trade Openness and $\mathrm{CO}_{2}$ Emissions: Evidence from Tunisia. Sustainability 11 (12), 3295. doi:10.3390/su11123295

Meirun, T., Mihardjo, L. W., Haseeb, M., Khan, S. A. R., and Jermsittiparsert, K. (2021). The Dynamics Effect of green Technology Innovation on Economic Growth and $\mathrm{CO}_{2}$ Emission in Singapore: New Evidence from Bootstrap ARDL Approach. Environ. Sci. Pollut. Res. 28 (4), 4184-4194. doi:10.1007/s11356-020-10760-w

Mukhtarov, S., Aliyev, S., Mikayilov, J. I., Ismayilov, A., and Rzayev, A. (2021). The FDI- $\mathrm{CO}_{2}$ Nexus from the Sustainable Development Perspective: The Case of Azerbaijan. Int. J. Sustain. Develop. World Ecol. 28 (3), 246-254. doi:10.1080/ 13504509.2020.1804479

Ncube, M., Soonawalla, K., and Hausken, K. (2021). The Links between Business Environment, Economic Growth and Social Equity: A Study of African Countries. J. Afr. Business 22 (1), 61-84. doi:10.1080/15228916.2019.1695184

Peng, B., Chen, S., Elahi, E., and Wan, A. (2021a). Can Corporate Environmental Responsibility Improve Environmental Performance? An Inter-Temporal Analysis of Chinese Chemical Companies. Environ. Sci. Pollut. Res. 28, 12190-12201. doi:10.1007/s11356-020-11636-9

Peng, B., Yan, W., Elahi, E., and Wan, A. (2021b). Does the green Credit Policy Affect the Scale of Corporate Debt Financing? Evidence from Listed Companies in Heavy Pollution Industries in China. Environ. Sci. Pollut. Res. 29, 755-767. doi:10.1007/s11356-021-15587-7

Peng, B., Zhang, X., Elahi, E., and Wan, A. (2022). Evolution of Spatial-Temporal Characteristics and Financial Development as an Influencing Factor of green Ecology. Environ. Dev. Sustain. 24 (1), 789-809. doi:10.1007/s10668-021$01469-\mathrm{y}$

Qin, L., Hou, Y., Miao, X., Zhang, X., Rahim, S., and Kirikkaleli, D. (2021). Revisiting Financial Development and Renewable Energy Electricity Role in Attaining China's Carbon Neutrality Target. J. Environ. Manage. 297, 113335. doi:10.1016/j.jenvman.2021.113335

Sebri, M., and Ben-Salha, O. (2014). On the Causal Dynamics between Economic Growth, Renewable Energy Consumption, $\mathrm{CO}_{2}$ Emissions and Trade Openness: Fresh Evidence from BRICS Countries. Renew. Sustain. Energ. Rev. 39, 14-23. doi:10.1016/j.rser.2014.07.033

Shahbaz, M., Solarin, S. A., Mahmood, H., and Arouri, M. (2013). Does Financial Development Reduce $\mathrm{CO}_{2}$ Emissions in Malaysian Economy? A Time Series Analysis. Econ. Model. 35, 145-152. doi:10.1016/j.econmod.2013.06.037

Shahbaz, M., Shahzad, S. J. H., Ahmad, N., and Alam, S. (2016). Financial Development and Environmental Quality: The Way Forward. Energy Policy 98, 353-364. doi:10.1016/j.enpol.2016.09.002
Shen, D., Xia, M., Zhang, Q., Elahi, E., Zhou, Y., and Zhang, H. (2019). The Impact of Public Appeals on the Performance of Environmental Governance in China: A Perspective of Provincial Panel Data. J. Clean. Prod. 231, 290-296. doi:10. 1016/j.jclepro.2019.05.089

Sheng, X., Peng, B., Elahi, E., and Wei, G. (2019). Regional Convergence of EnergyEnvironmental Efficiency: From the Perspective of Environmental Constraints. Environ. Sci. Pollut. Res. 26 (25), 25467-25475. doi:10.1007/s11356-019-05749-z

Tyagi, S., Garg, N., Garg, N., and Paudel, R. (2014). Environmental Degradation: Causes and Consequences. Eur. Res. 81 (8-2), 1491-1498. doi:10.13187/er.2014.81.1491

Usman, M., Balsalobre-Lorente, D., Jahanger, A., and Ahmad, P. (2022). Pollution Concern during Globalization Mode in Financially Resource-Rich Countries: Do Financial Development, Natural Resources, and Renewable Energy Consumption Matter? Renew. Energ. 183, 90-102. doi:10.1016/j.renene.2021.10.067

Wang, Y., Peng, B., Wei, G., and Elahi, E. (2019). Comprehensive Evaluation and Spatial Difference Analysis of Regional Ecological Carrying Capacity: A Case Study of the Yangtze River Urban Agglomeration. Int. J. Envir. Res. Publ. Heal. 16 (18), 3499. doi:10.3390/ijerph16183499

Wang, F., Cai, W., and Elahi, E. (2021). Do Green Finance and Environmental Regulation Play a Crucial Role in the Reduction of CO2 Emissions? An Empirical Analysis of 126 Chinese Cities. Sustainability 13 (23), 13014. doi:10.3390/su132313014

Yuxiang, K., and Chen, Z. (2011). Financial Development and Environmental Performance: Evidence from China. Envir. Dev. Econ. 16 (1), 93-111. doi:10. 1017/S1355770X10000422

Zakaria, M., and Bibi, S. (2019). Financial Development and Environment in South Asia: the Role of Institutional Quality. Environ. Sci. Pollut. Res. 26 (8), 7926-7937. doi:10.1007/s11356-019-04284-1

Zhang, L., Godil, D. I., Bibi, M., Khan, M. K., Sarwat, S., and Anser, M. K. (2021). Caring for the Environment: How Human Capital, Natural Resources, and Economic Growth Interact with Environmental Degradation in Pakistan? A Dynamic ARDL Approach. Sci. Total Environ. 774, 145553. doi:10.1016/j. scitotenv.2021.145553

Zhao, B., and Yang, W. (2020). Does Financial Development Influence $\mathrm{CO}_{2}$ Emissions? A Chinese Province-Level Study. Energy 200, 117523. doi:10. 1016/j.energy.2020.117523

Zhao, X., Peng, B., Elahi, E., Zheng, C., and Wan, A. (2020). Optimization of Chinese Coal-Fired Power Plants for Cleaner Production Using Bayesian Network. J. Clean. Prod. 273, 122837. doi:10.1016/j.jclepro.2020.122837

Zhao, Y., Peng, B., Elahi, E., and Wan, A. (2021). Does the Extended Producer Responsibility System Promote the green Technological Innovation of Enterprises? An Empirical Study Based on the Difference-In-Differences Model. J. Clean. Prod. 319, 128631. doi:10.1016/j.jclepro.2021.128631

Zheng, C., Peng, B., XinSheng, E., Elahi, E., and Wan, A. (2020). Strategies of Haze Risk Reduction Using the Tripartite Game Model. Complexity 2020, 1-11. doi:10.1155/2020/6474363

Zhong, Z., Peng, B., and Elahi, E. (2021). Spatial and Temporal Pattern Evolution and Influencing Factors of Energy-Environmental Efficiency: A Case Study of Yangtze River Urban Agglomeration in China. Energ. Environ. 32 (2), 242-261. doi:10.1177/0958305x20923114

Conflict of Interest: The authors declare that the research was conducted in the absence of any commercial or financial relationships that could be construed as a potential conflict of interest.

Publisher's Note: All claims expressed in this article are solely those of the authors and do not necessarily represent those of their affiliated organizations, or those of the publisher, the editors, and the reviewers. Any product that may be evaluated in this article, or claim that may be made by its manufacturer, is not guaranteed or endorsed by the publisher.

Copyright $\odot 2022$ Huo, Ullah, Zulfiqar, Parveen and Kibria. This is an open-access article distributed under the terms of the Creative Commons Attribution License (CC BY). The use, distribution or reproduction in other forums is permitted, provided the original author(s) and the copyright owner(s) are credited and that the original publication in this journal is cited, in accordance with accepted academic practice. No use, distribution or reproduction is permitted which does not comply with these terms. 